\title{
Utilization of Iron Ore Tailing for the Preparation of $\alpha-\mathrm{Fe}_{2} \mathrm{O}_{3}$ nanoparticles
}

\author{
Xiaodong XU, Yanxi DENG \\ School of Materials Science and Technology \\ China University of Geosciences \\ Beijing, China \\ e-mail: 1763480627@qq.com,dengyx@cugb.edu.cn
}

\begin{abstract}
The objective of this study was to recover the iron from the iron ore tailing and convert it into a value-added products like $\alpha-\mathrm{Fe}_{2} \mathrm{O}_{3}$ nanoparticles with photocatalytic properties. Iron was extracted from the iron ore tailing by using acid leaching method and the leaching parameters were discussed. When the amount and concentration of $\mathrm{HCl}$, leaching reaction temperature and time were fixed at $21.4 \mathrm{ml}$, $30 \%, 100^{\circ} \mathrm{C}$ and $1.5 \mathrm{~h}$, respectively, the iron recovery reached 99.63\%. Mesoporous $\alpha-\mathrm{Fe}_{2} \mathrm{O}_{3}$ nanoparticles were successfully prepared by a facile precipitation method using the acid leaching solution as the iron source. The $\alpha-\mathrm{Fe}_{2} \mathrm{O}_{3}$ samples were characterized by XRD, SEM, $\mathrm{N}_{2}$ adsorption and UV-Vis spectroscopy. The crystallite size of $\alpha-\mathrm{Fe}_{2} \mathrm{O}_{3}$ was about $36 \mathrm{~nm}$ and the specific surface area was $46.03 \mathrm{~m}^{2} / \mathrm{g}$. The mesoporous $\alpha-\mathrm{Fe}_{2} \mathrm{O}_{3}$ prepared from iron ore tailing displayed better photocatalytic activity for the degradation of methylene blue, which was similar to that of $\alpha-\mathrm{Fe}_{2} \mathrm{O}_{3}$ prepared from pure agent.
\end{abstract}

\section{Keywords-iron ore tailing; preparation; nanoparticles}

\section{INTRODUCTION}

Iron ore tailing, industrial solid wastes produced from mineral beneficiation process, usually have high contents of $\mathrm{SiO}_{2}$ and $\mathrm{Fe}_{2} \mathrm{O}_{3}$, which enables it to be a potential source of silicon and iron. Many researchers utilize this waste for its possible applications. Some researchers have synthesized magnetite nanoparticles by various methods using $\mathrm{Fe}$ containing solution extracted from the iron ore tailing [1-5]. Yu et al. [6] have successfully synthesized highly ordered mesoporous materials by hydrothermal method using sodium silicate extracted from iron ore tailing as silica source. In our previous work, MCM-41 was synthesized by non-hydrothermal method using sodium silicate produced by acid leaching of iron ore tailing and subsequent alkali leaching of acid insoluble residue $[7,8]$. Extraction of silicon and iron from the iron ore tailing by leaching method and converting them into value-added products can alleviate the pressure of mining solid wastes on the environment and have important economic and environmental implications.

$\alpha-\mathrm{Fe}_{2} \mathrm{O}_{3}$ can degrade an extensive variety of contaminants and display excellent photocatalytic activity, due to its small particles size, large specific surface area, non-toxicity and chemical stability. Various synthetic methods have been reported to synthesize $\alpha-\mathrm{Fe}_{2} \mathrm{O}_{3}$, including precipitation [9], sol-gel method [10], hydrothermal synthesis [11], thermal decomposition technique [12]. However, pure agents such as $\mathrm{Fe}_{2}\left(\mathrm{SO}_{4}\right)_{3}, \mathrm{Fe}\left(\mathrm{NO}_{3}\right)_{3}$ and $\mathrm{FeCl}_{3}$ are used in the synthesis of $\alpha-\mathrm{Fe}_{2} \mathrm{O}_{3}$. Hence, it is of significant interest to develop a simple, inexpensive method to prepare nanocrystalline $\alpha-\mathrm{Fe}_{2} \mathrm{O}_{3}$ with excellent properties. To the best of authors' knowledge, no attempt to use iron ore tailing as the source of iron in synthesizing $\mathrm{Fe}_{2} \mathrm{O}_{3}$ nanoparticles for the photocatalytic application has been reported.

In this paper, we report the preparation of mesoporous $\alpha$ $\mathrm{Fe}_{2} \mathrm{O}_{3}$ from iron ore tailing. Iron was first extracted from the iron ore tailing by using acid leaching. $\alpha-\mathrm{Fe}_{2} \mathrm{O}_{3}$ nanoparticles were then prepared by precipitation method using pure $\mathrm{FeCl}_{3}$ solution extracted from the iron ore tailing as iron source. The phase structure and particle morphology were analyzed by XRD and SEM. The photocatalytic properties of $\alpha-\mathrm{Fe}_{2} \mathrm{O}_{3}$ nanoparticles were determined by degradation methylene blue under the ultraviolet irradiation conditions. For comparison, $\alpha-\mathrm{Fe}_{2} \mathrm{O}_{3}$ nanoparticles were also prepared from pure agent $\left(\mathrm{FeCl}_{3} \cdot 6 \mathrm{H}_{2} \mathrm{O}\right)$.

\section{EXPERIMENTAL}

\section{A. Materials}

Iron ore tailing was collected from the tailing ponds of iron ore dressing plant (Ma'anshan iron and steel company). The major constituents were $\mathrm{SiO}_{2}(50.88 \%), \mathrm{Fe}_{2} \mathrm{O}_{3}(25.18 \%)$ and $\mathrm{Al}_{2} \mathrm{O}_{3}(13.62 \%)$. The major minerals were hematite, silica and kaolinite. $\mathrm{HCl}$ was used as leaching agent for the extraction of iron sources from iron ore tailing. $\mathrm{NaOH}$ was used as preparation agent. Hydrogen peroxide was used as an oxidant. All chemicals were analytical grade.

\section{B. Extraction of iron from iron ore tailing}

Acid leaching method was adopted to extract the iron source from iron ore tailing. In order to extract the iron species in an optimized condition, various parameters, such as $\mathrm{HCl}$ concentration, $\mathrm{HCl}$ amount, leaching reaction temperature and time were investigated. A weighted amount of iron ore tailing was digested with $\mathrm{HCl}$ in an oil bath. The resulting suspension was filtered, obtaining the filtrate and the acid insoluble residue. The filtrate was $\mathrm{FeCl}_{3}$ solution with some other impurity ions and used as the iron source for the synthesis of $\mathrm{Fe}_{2} \mathrm{O}_{3}$ nanoparticles.

\section{Synthesis of $\alpha-\mathrm{Fe}_{2} \mathrm{O}_{3}$}

$\alpha-\mathrm{Fe}_{2} \mathrm{O}_{3}$ was synthesized by precipitation using the leaching solution as the iron source. Firstly, $\mathrm{NaOH}$ solution (3mol/L) was added drop-by-drop into the $100 \mathrm{~mL}$ leaching solution until $\mathrm{pH}=5$, and vigorously to form the precipitate. Secondly, the resulting precipitate was washed several times 
and redissolved in $\mathrm{HCl}$ solution and then reprecipitated as iron hydroxide with $\mathrm{NaOH}$, and then filtered. Thirdly, the resulting precipitate was washed several times until it is free from chlorides and then oven dried at $100{ }^{\circ} \mathrm{C}$ for $12 \mathrm{~h}$. The dried product was calcined at $500{ }^{\circ} \mathrm{C}$ for $2 \mathrm{~h}$ and then $\alpha$ $\mathrm{Fe}_{2} \mathrm{O}_{3}$ was obtained.

\section{Characterization of $\mathrm{Fe}_{2} \mathrm{O}_{3}$}

$\mathrm{X}$-ray diffraction (XRD) analysis was performed with a D/MAX 2000 powder diffractometer using $\mathrm{Cu} \mathrm{K \alpha}$ radiation $(40 \mathrm{kv}, 100 \mathrm{~mA}, \lambda=0.154056 \mathrm{~nm})$. The surface morphology of the materials was examined using HITACHI S-4300 microscope. Nitrogen adsorption-desorption isotherms were determined by a Quadrasorb SI-MP. The specific surface area of the sample was calculated by the BET method. UVvis absorption spectra were recorded using Varian Cary $5000 \mathrm{UV}$-vis spectrophotometer.

\section{E. Photocatalytic experiment}

The photocatalytic activities of the prepared samples were measured by the photocatalytic degradation of methylene blue under ultraviolet irradiation. The catalyst dosage was $0.02 \mathrm{~g}$ and the initial concentration of $\mathrm{MB}$ was $20 \mathrm{mg} / \mathrm{L}$ of $\mathrm{MB}$ solution $(50 \mathrm{ml})$. Prior to each test, the suspension were kept in the darkness under magnetic stirring for 60 minutes in order to reach the adsorption equilibrium. After adding $0.03 \mathrm{~mL}$ of a $30 \%$ hydrogen peroxide $\left(\mathrm{H}_{2} \mathrm{O}_{2}\right)$ solution as an oxidant, the lamp was turned on. At a given time intervals, the suspension was sampled, the catalyst powder was recovered by centrifugation and the mother liquor was checked by UVVIS analysis. According to the change in the concentration of $\mathrm{MB}$, the degradation rate $(\eta)$ versus time was calculated by Equation $\eta=\frac{C_{t}}{C_{0}} \times 100 \%$, where $\mathrm{C}_{0}$ and $\mathrm{C}_{\mathrm{t}}$ were the initial concentration and the concentration at time $t$ of $\mathrm{MB}$, respectively. For all experiments, each reported value is the average of three replicate samples.

\section{RESULTS AND DISCUSSION}

\section{A. Extraction of iron source from iron ore tailing}

Acid leaching method was adopted to extract iron from the iron ore tailing. The hematite from the iron ore tailing could react with $\mathrm{HCl}$ as the following reaction: $\mathrm{Fe}_{2} \mathrm{O}_{3}+6 \mathrm{H}^{+}=2 \mathrm{Fe}^{3+}+3 \mathrm{H}_{2} \mathrm{O}$. In order to obtain the optimal conditions for iron recovery from the iron ore tailing, the effects of the amount and concentration of $\mathrm{HCl}$, leaching reaction temperature and time on the iron recovery efficiency were studied. Based on the optimized set of conditions with respect to $\mathrm{HCl}$ concentration, amount of $\mathrm{HCl}$ and reaction temperature, $10 \mathrm{~g}$ iron ore tailings were mixed with $21.4 \mathrm{ml} 30 \% \mathrm{HCl}$ at $100^{\circ} \mathrm{C}$ for a certain time, the results were shown in Fig. 1. The results showed that when the amount of $\mathrm{HCl}$, the concentration of $\mathrm{HCl}$ and reaction temperature are fixed at $21.4 \mathrm{ml}, 30 \%$ and $100{ }^{\circ} \mathrm{C}$, respectively, the iron recovery increased with increasing reaction time. When the reaction time was $1.5 \mathrm{~h}$, the iron recovery reached $99.63 \%$. The leaching solution was $\mathrm{FeCl}_{3}$ solution with some impurity ions and iron concentration was $12.26 \mathrm{~g} / \mathrm{L}$ under these optimal conditions, which was the iron source of synthesizing nano- $\mathrm{Fe}_{2} \mathrm{O}_{3}$. The chemical composition of the left acid insoluble residue are predominant $\mathrm{SiO}_{2}(77.10 \%)$ and $\mathrm{Al}_{2} \mathrm{O}_{3}(13.84 \%)$ and minor $\mathrm{Fe}_{2} \mathrm{O}_{3}(1.15 \%)$. From these results, it could be seen that acid leaching was an efficient method for iron extraction from iron ore tailing. Acid leaching removed hematite from the iron ore tailing and produced an acid insoluble residue containing quartz and kaolinite, which resulted in a high reduction in the $\mathrm{Fe}_{2} \mathrm{O}_{3}$ content and increase in the silica of the left insoluble residue.

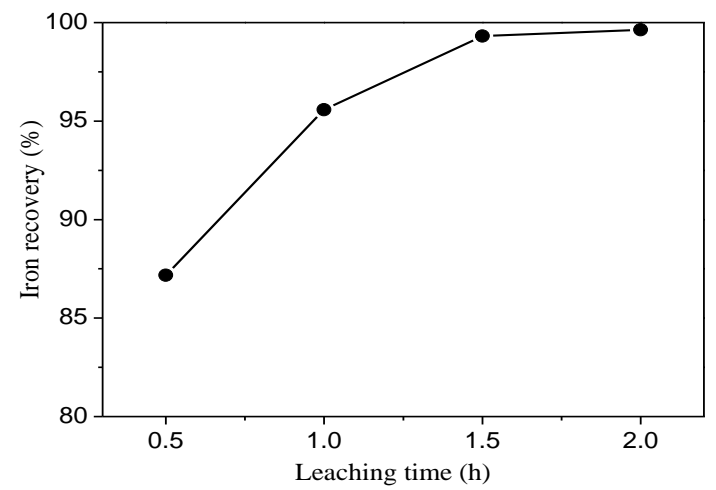

Figure 1. Effect of reaction time on the iron recovery from iron ore tailing.

\section{B. Characterization of $\alpha-\mathrm{Fe}_{2} \mathrm{O}_{3}$}

Fig. 2 was the XRD pattern of $\alpha-\mathrm{Fe}_{2} \mathrm{O}_{3}$ prepared from iron ore tailing. The major diffraction peaks are consistent with the data of standard $\alpha-\mathrm{Fe}_{2} \mathrm{O}_{3}$ sample. No detectable impurities were noted in the XRD pattern. This demonstrated that the prepared sample was composed of high purity $\alpha-\mathrm{Fe}_{2} \mathrm{O}_{3}$. The average crystallite size of the prepared $\alpha-\mathrm{Fe}_{2} \mathrm{O}_{3}$ was calculated from the XRD data by the Debye-Scherrer equation and found to be $36 \mathrm{~nm}$.

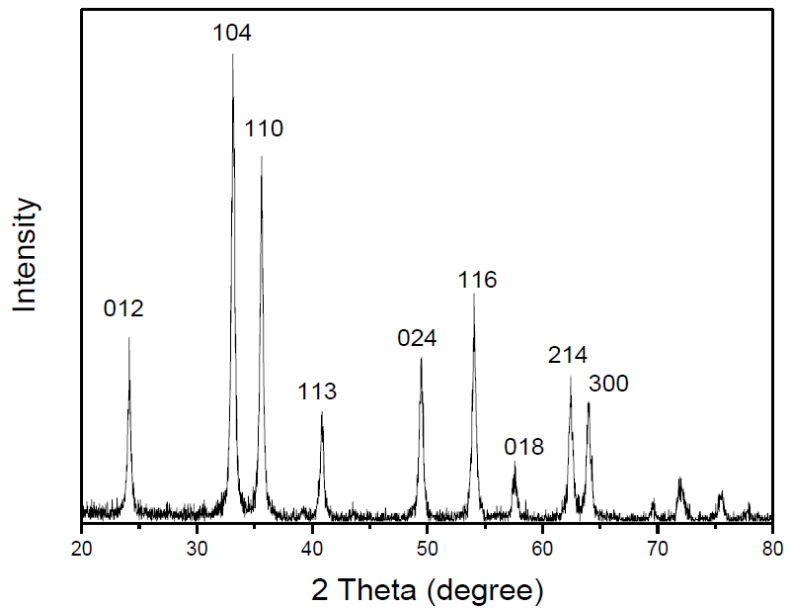

Figure 2. XRD pattern of the prepared $\alpha-\mathrm{Fe}_{2} \mathrm{O}_{3}$. 
The size and morphology of the prepared $\alpha-\mathrm{Fe}_{2} \mathrm{O}_{3}$ were examined by SEM analysis (Fig.3). The product was composed of nanoparticles with sizes range from 20 to ca.40 nm. Agglomerated particles were also observed.

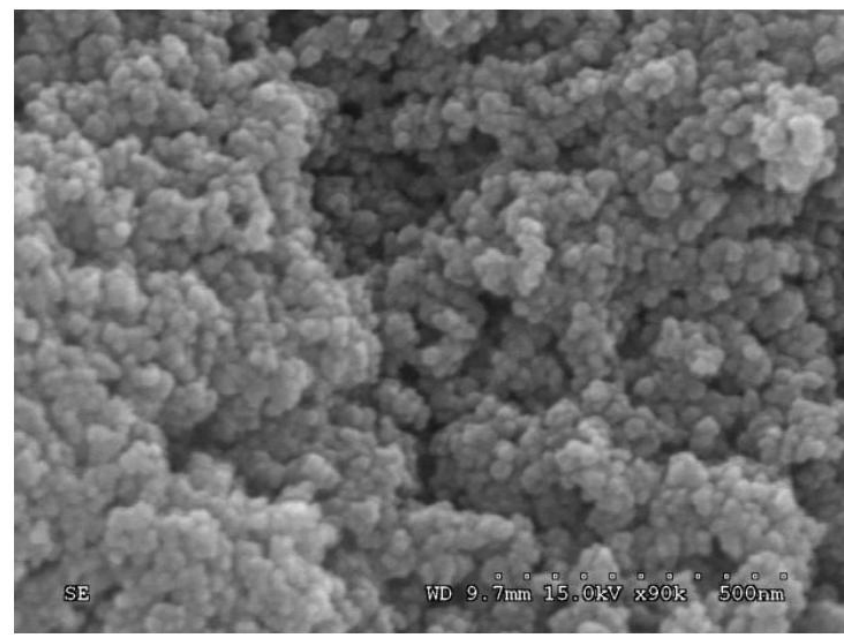

Figure 3. SEM image of the prepared $\alpha-\mathrm{Fe}_{2} \mathrm{O}_{3}$.

Nitrogen adsorption-desorption isotherm of the prepared $\alpha-\mathrm{Fe}_{2} \mathrm{O}_{3}$ was shown in Fig. 4 (a). The isotherms exhibited Type IV isotherm with H2-type hysteresis loop on the bases of the IUPAC classification, which is the characteristic of mesoporous materials. Based on Barrer-Joyner-halenda (BJH) method, the corresponding pore size distribution of the sample was obtained and the result was shown in Fig. 4 (b). It can be seen that the pore size distribution of the sample was in the range of 4-50 nm with predominant pore diameter around at $12.7 \mathrm{~nm}$. The Brunauer-Emmett-Teller (BET) specific surface area was calculated to be $46.031 \mathrm{~m}^{2} / \mathrm{g}$, which was over the value of the $\alpha-\mathrm{Fe}_{2} \mathrm{O}_{3}$ prepared from pure agent $\left(45.531 \mathrm{~m}^{2} / \mathrm{g}\right)$.

The optical properties of the prepared $\alpha-\mathrm{Fe}_{2} \mathrm{O}_{3}$ was investigated by the UV-Vis absorbance studies. As shown in Fig.5, the prepared $\alpha-\mathrm{Fe}_{2} \mathrm{O}_{3}$ has strong photo absorption in the UV and visible spectral regions, and the absorption edge

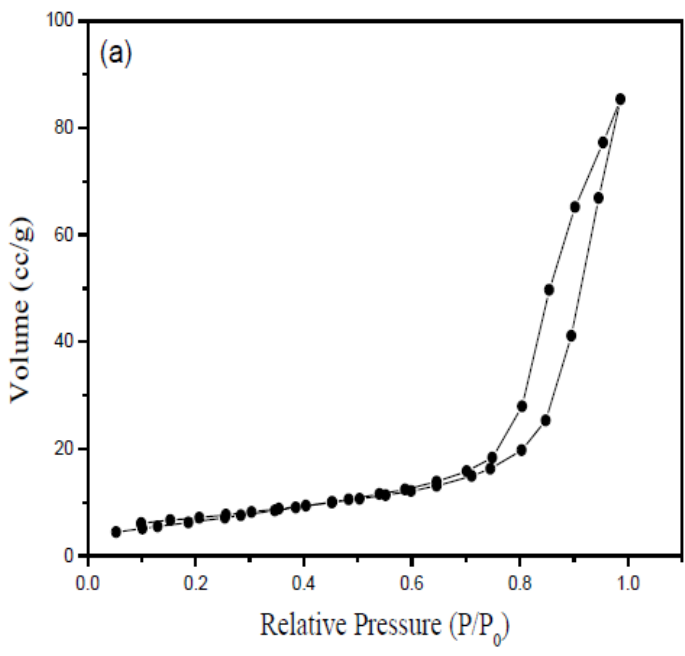

appears at $610 \mathrm{~nm}$. The band gap energy was calculated according to the Tauc's equation $(\alpha h v)^{1 / n}=\mathrm{A}\left(\mathrm{h} v-\mathrm{E}_{\mathrm{g}}\right)$, where, $\alpha$ is the absorption coefficient, h $v$ is the incident photon energy, $\mathrm{A}$ is a constant, $\mathrm{E}_{\mathrm{g}}$ is the band gap energy and $\mathrm{n}$ is the exponent $(n=2$ or $1 / 2$ for indirect or direct transition). The intercept of the straight line at $(\alpha h v)^{2}=0$ in the plot $(\alpha h v)^{2}$ versus $h v$ (Fig.5 inset), gave the value of $E_{g}$ correspondence to $2.03 \mathrm{eV}$, which was consistent with the reported value $\left(\mathrm{E}_{\mathrm{g}}=1.9-2.2 \mathrm{eV}\right)[13]$.

\section{Photocatalytic properties}

The photocatalytic activity of the sample was evaluated by the degradation of methylene blue in aqueous solution under ultraviolet light. Fig. 6 represented the degradation efficiency as a function of time. After adsorption in the dark for $60 \mathrm{~min}$, the degradation efficiency was very low and there were no obvious adsorption. This indicated that adsorption of dye might not be the most important factor for degradation activity of $\alpha-\mathrm{Fe}_{2} \mathrm{O}_{3}$ in this study. After UV irraditation for $25 \mathrm{~min}$, the degradation efficiency reached $96.2 \%$. These results showed that $\alpha-\mathrm{Fe}_{2} \mathrm{O}_{3}$ displayed excellent photocatalytic properties under UV irradiation. It could be also seen that the efficiency of $\alpha-\mathrm{Fe}_{2} \mathrm{O}_{3}$ prepared from iron ore tailing was slightly smaller than that of $\alpha$ $\mathrm{Fe}_{2} \mathrm{O}_{3}$ prepared from pure agent.

Fig. 7 was the changes in the UV-vis absorbance spectra in the presence of $\mathrm{MB}$ aqueous solution under UV irradiation for different time. The MB spectrum reveals a major absorption band at $664 \mathrm{~nm}$. After adsorption in the dark for $60 \mathrm{~min}$, the intensity of absorption peak declined slightly. After UV irradiation, the characteristic absorption peak declined rapidly in intensity with prolong irradiation time and disappeared completely after irradiation for $25 \mathrm{~min}$. These results indicated that the degradation of $\mathrm{MB}$ took place by the photocatalytic activity of $\alpha-\mathrm{Fe}_{2} \mathrm{O}_{3}$, not for the catalytic activity or adsorption on the catalyst [14]. These results indicated that the prepared $\alpha-\mathrm{Fe}_{2} \mathrm{O}_{3}$ from iron ore tailing was a promising photocatalyst for the degradation of organic pollutants.

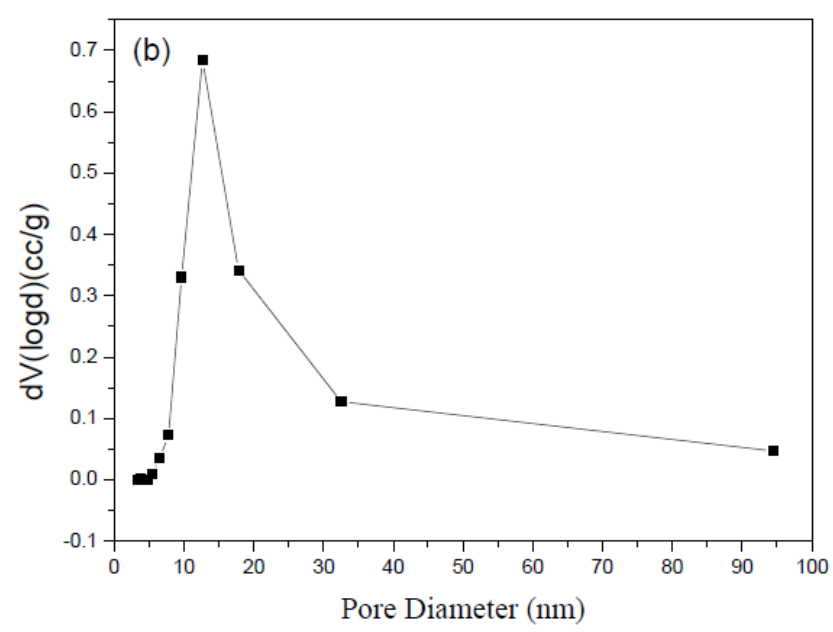

Figure 4. Nitrogen adsorption-desorption isotherm (a) and pore size distribution (b) of the prepared $\alpha-\mathrm{Fe}_{2} \mathrm{O}_{3}$. 


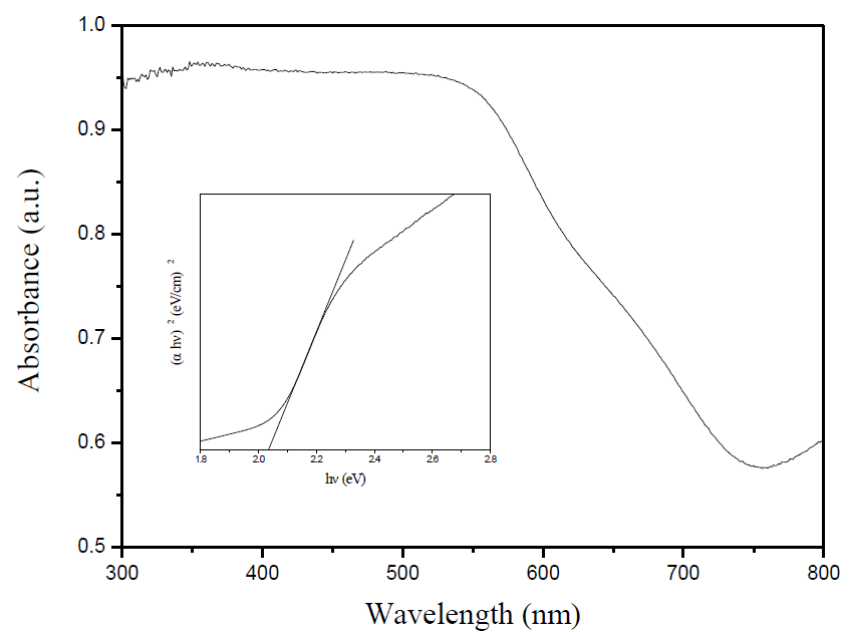

Figure 5. UV-Vis absorbance spectra of the prepared $\alpha-\mathrm{Fe}_{2} \mathrm{O}_{3}$ (inset, plot of the square of absorbance versus photon energy).

\section{CONCLUSION}

Mesoporous $\alpha-\mathrm{Fe}_{2} \mathrm{O}_{3}$ was successfully synthesized by a facile precipitation method using the high purity iron separated from iron ore tailing as iron source. The crystallite size of $\alpha-\mathrm{Fe}_{2} \mathrm{O}_{3}$ was about $36 \mathrm{~nm}$ and the specific surface area was $46.03 \mathrm{~m}^{2} / \mathrm{g}$. The mesoporous $\alpha-\mathrm{Fe}_{2} \mathrm{O}_{3}$ prepared from iron ore tailing displayed better photocatalytic activity for the degradation of methylene blue.

\section{ACKNOWLEDGMENT}

This work was supported by the national Natural Science Foundation of China (51574209).

\section{REFERENCES}

[1] R. Kumar, R. Sakthivel, R. Behura, B.K. Mishra, D.Das. Synthesis of magnetic nanoparticles from mineral waste. Journal of Alloys and Compounds 645 (2015) 398-40

[2] R. Sakthivel, N. Vasumathi, D. Sahu, B. K. Mishra. Synthesis of magnetite powder from iron ore tailings. Powder Technology 201 (2010) 187-190.

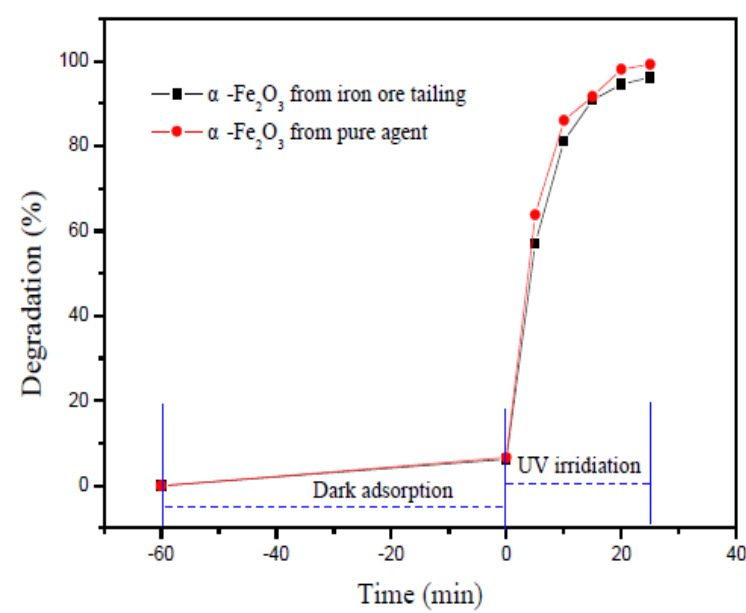

Figure 6. Photocatalytic degradation rates of MB by the prepared $\alpha$ $\mathrm{Fe}_{2} \mathrm{O}_{3}$ under UV irradiation.
[3] S.K. Giri, N.N. Das , G.C. Pradhan. Magnetite powder and kaolinite derived from waste iron ore tailings for environmental applications. Powder Technology 214 (2011) 513-518

[4] S.K. Giri, N.N. Dasb, G.C. Pradhana. Synthesis and characterization of magnetite nanoparticles using waste iron ore tailings for adsorptive removal of dyes from aqueous solution. Colloids and Surfaces A: Physicochem. Eng. Aspects 389 (2011) 43- 49

[5] S. Wu, A.Z Sun, F.Q. Zhai, J. Wang, W.H. Xu, Q. Zhang, A. A. Volinsky. $\mathrm{Fe}_{3} \mathrm{O}_{4}$ magnetic nanoparticles synthesis from tailings by ultrasonic chemical co-precipitation. Materials letters 65 (2011) 1882-1884

[6] H.H. Yu, X.X. Xue, D.W. Huang. Synthesis of mesoporous silica materials (MCM-41) from iron ore tailings. Materials Research Bulletin 44 (2009) 2112-2115

[7] G. Yang, Y.X. Deng, H. Ding, Z.X. Lin, Y.K. Shao, Y. Wang. A facile approach to synthesizeMCM-41mesoporousmaterials from iron ore tailing: Influence of the synthesis conditions on the structural properties. Applied Clay Science 111 (2015) 61-66

[8] G. Yang, Y.X. Deng, J. Wang. Non-hydrothermal Synthesis and characterization of MCM-41 mesoporous materials from iron ore tailing. Ceramics International 40 (2014) 7401-7406

[9] S. Boumaza, A. Boudjemaa, S. Omeiri, R. Bouarab, A. Bouguelia, M. Trari. Physical and photoelectrochemical characterizations of hematite a- $\mathrm{Fe}_{2} \mathrm{O}_{3}$ : Application to photocatalytic oxygen evolution. Solar Energy 84 (2010) 715-721

[10] H.N. Liang, K. Liu, Y.H. Ni. Synthesis of mesoporous $\alpha-\mathrm{Fe}_{2} \mathrm{O}_{3}$ via sol-gel methods using cellous nano-crystals (CNC) as template and its photo-catalytic properties. Materials letters 159 (2015) 218-220

[11] Z. Liua, B.L. Lva, D. Wua, Y.H. Suna, Y. Xua. Magnetic and electrochemical behavior of rhombohedral $\alpha-\mathrm{Fe}_{2} \mathrm{O}_{3}$ nanoparticles with (104) dominant facets. Particuology 11 (2013) 327-333

[12] S.J. Maji, N. Mukherjee, A.Mondal, B. Adhikary. Synthesis, characterization and photocatalytic activity of $\alpha-\mathrm{Fe}_{2} \mathrm{O}_{3}$ nanoparticles. Polyhedron 33 (2012) 145-149

[13] Z.Q. Cao, M.L. Qin, B.R. Jia, Y.R. Gu, P.Q. Chen, A.A. Volinsky, X.H. Qu. One pot solution combustion synthesis of highly mesoporous hematite for photocatalysis. Ceramics International 41 (2015) 2806-2812

[14] C.C. Wang, C.K. Lee, M.D. Lyu, L.C. Juang. Photocatalytic degradation of C.I. Basic Violet 10 using $\mathrm{TiO}_{2}$ catalyst supported by Y. Zeolite: An investigation of the effects of operational parameters. Dyes and Pigments 76 (2008) 817-824.

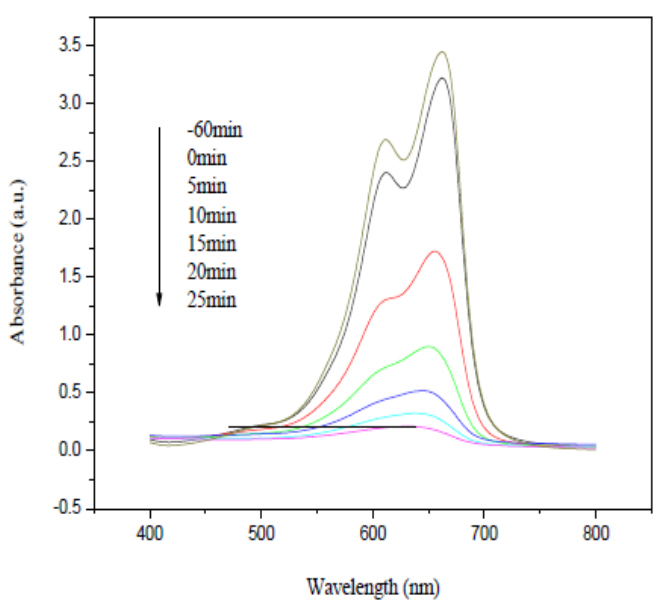

Figure 7. Changes of the time-dependent UV-vis absorbance spectra in the presence of $\alpha-\mathrm{Fe}_{2} \mathrm{O}_{3}$ under UV irradiation for different amount of time. 